\title{
Ecological Validity in the Critical Care Environment: Closing the Loop on Evidence Based Medicine
}

The lifecycle of patient care innovations often begins with clinicians making practical observations at their patients' bedside, reflecting on physiologic principles, and considering "How could we do this better?" The most promising ideas emerge from this real-world environment and travel through a process intended to refine the method and confirm its utility: retrospective analyses to look for a signal of effect, pilot studies intended to standardize and evaluate the feasibility of the intervention in question, and then larger-scope investigations structured to maximize the studies' statistical power and internal validity using techniques like blinding and randomization. There has been considerable focus in recent years on the vexing problem of irreproducibility in scientific research across the spectrum of life sciences, from basic cancer research to clinical trials. ${ }^{1,2}$ Consequently, definitive studies typically enroll a highly selective study population and use rigid study protocols. Each step along the path to the accepted standard, double-blind, placebo-controlled, multi-center trial adjusts the patient population and intervention such that positive trial results are often based on data derived from a relatively artificial context.

What is seldom appreciated is that a completed multicenter trial is not the end point of a journey that translates ideas into practice, but a midpoint. Crucial questions remain. First, could this intervention be applied to other defined, related conditions or populations, which we refer to as the external validity of the study results? ${ }^{3}$ Research in the critical care environment is particularly challenging due to the great heterogeneity of index diseases and comorbidities in the subjects, such that a related question of even greater uncertainty arises: Do the results of this study generalize to the patients I care for in the medical system

The author has disclosed a relationship with the National Institutes of Health (grant K23NS092975).

The content of this work is solely the responsibility of the authors and does not necessarily represent the official views of the National Institutes of Health.

Correspondence: Dr. Matthew Maas, 710 N Lake Shore Drive, 11th Floor, Department of Neurology, Chicago, IL 60611. E-mail: mbmaas@northwestern.edu.

DOI: $10.4187 /$ respcare. 06015 in which I work? In our field, it would be helpful to borrow a concept from the psychology and sociology literatureecological validity - which refers to the generalizability of an intervention or effect observable in a study into the real

\section{See the Original Study on Page 1}

world, devoid of the distortions and biases of clinical trials: usual practice environments, with practitioners of typical skills and training, hospitals with typical resources and staffing, and without confounders like selection bias and the Hawthorne effect.

Although the term ecological validity may be unfamiliar to some respiratory care providers, relevant examples are not. One well-known illustration is the research on resuscitation of septic shock, where the findings of an initial landmark trial have failed replication in multiple subsequent confirmatory trials. ${ }^{4-7}$ Evidence-based interventions of great interest to readers of this journal are the practices of minimizing sedative exposure and utilizing daily spontaneous breathing trials for the sake of optimal liberation from mechanical ventilation. ${ }^{8-11}$ In this issue of Respiratory CARE, Kallet and colleagues ${ }^{12}$ provide crucial data to confirm the ecological validity of these related practices. Their institution responded to the emerging data on sedation usage and spontaneous breathing trials by implementing protocols to target light sedation and enact daily spontaneous breathing trials across multiple patient populations in 2 different ICUs. Using a registry of subjects treated for ARDS, a particularly morbid and challenging subpopulation of ventilated patients, they compared outcomes from the pre-implementation and postimplementation periods. They observed impressive improvements: reductions in the median duration of mechanical ventilation from $14 \mathrm{~d}$ to $9 \mathrm{~d}$ and ICU length of stay from $18 \mathrm{~d}$ to $13 \mathrm{~d}$ (both $P<.001$ ), differences that persisted even after adjustment for potential confounders.

Greater attention and resources should be devoted to studies, such as this one, that confirm or refute the applicability of clinical trial findings in commonplace practice. Implementation of basic guideline recommendations for ARDS care remains poor despite positive physician attitudes toward their utility. ${ }^{13,14}$ Implementing new protocols is a cumbersome and costly process, requiring educational 


\section{EDITORIALS}

initiatives, shifts in ingrained cultures of practice, staffing demands, capital investments, and quality-assurance feedback. Positive results of major clinical trials represent a value proposition, whereas ecological validity studies close the loop on the evidence-based medicine pathway and bring innovative ideas back to the bedside where they began.

Matthew B Maas MD Division of Critical Care Departments of Neurology and Anesthesiology Northwestern University Feinberg School of Medicine Chicago, Illinois

\section{REFERENCES}

1. Begley CG, Ellis LM. Drug development: raise standards for preclinical cancer research. Nature 2012;483(7391):531-533.

2. Ebrahim S, Sohani ZN, Montoya L, Agarwal A, Thorlund K, Mills EJ, et al. Reanalyses of randomized clinical trial data. JAMA 2014; 312(10):1024-1032.

3. Steckler A, McLeroy KR. The importance of external validity. Am J Public Health 2008;98(1):9-10.

4. Rivers E, Nguyen B, Havstad S, Ressler J, Muzzin A, Knoblich B, et al. Early goal-directed therapy in the treatment of severe sepsis and septic shock. N Engl J Med 2001;345(19):1368-1377.

5. ProCESS Investigators, Yealy DM, Kellum JA, Huang DT, Barnato AE, Weissfeld LA, et al. A randomized trial of protocol-based care for early septic shock. N Engl J Med 2014;370(18):1683-1693.

6. ARISE Investigators, ANZICS Clinical Trials Group, Peake SL, Delaney A, Bailey M, Bellomo R, et al. Goal-directed resuscitation for patients with early septic shock. N Engl J Med 2014;371(16): 1496-1506.

7. Mouncey PR, Osborn TM, Power GS, Harrison DA, Sadique MZ, Grieve RD, et al. Trial of early, goal-directed resuscitation for septic shock. N Engl J Med 2015;372(14):1301-1311.

8. Esteban A, Frutos F, Tobin MJ, Alia I, Solsona JF, Valverdu I, et al. A comparison of four methods of weaning patients from mechanical ventilation. Spanish Lung Failure Collaborative Group. N Engl J Med 1995;332(6):345-350.

9. Ely EW, Baker AM, Dunagan DP, Burke HL, Smith AC, Kelly PT, et al. Effect on the duration of mechanical ventilation of identifying patients capable of breathing spontaneously. N Engl J Med 1996; 335(25):1864-1869.

10. Kress JP, Pohlman AS, O'Connor MF, Hall JB. Daily interruption of sedative infusions in critically ill patients undergoing mechanical ventilation. N Engl J Med 2000;342(20):1471-1477.

11. Girard TD, Kress JP, Fuchs BD, Thomason JW, Schweickert WD, Pun BT, et al. Efficacy and safety of a paired sedation and ventilator weaning protocol for mechanically ventilated patients in intensive care (Awakening and Breathing Controlled Trial): a randomised controlled trial. Lancet 2008;371(9607):126-134.

12. Kallet RH, Zhuo H, Yip V, Gomez A, Lipnick MS. Spontaneous breathing trials and conservative sedation practices reduce mechanical ventilation duration in subjects with ARDS. Respir Care 2017; doi: 10.4187/respcare.05270. [Epub ahead of print]

13. Weiss CH, Baker DW, Weiner S, Bechel M, Ragland M, Rademaker A, et al. Low tidal volume ventilation use in acute respiratory distress syndrome. Crit Care Med 2016;44(8):1515-1522.

14. Weiss CH, Baker DW, Tulas K, Weiner S, Bechel M, Rademaker A, et al. A critical care clinician survey comparing attitudes and perceived barriers to low tidal volume ventilation with actual practice. Ann Am Thorac Soc 2017; doi: 10.1513/AnnalsATS.201612-973OC. [Epub ahead of print] 